\title{
Musculação, uso de esteróides anabolizantes e percepção de risco entre jovens fisiculturistas de um bairro popular de Salvador, Bahia, Brasil
}

\author{
Body-building, steroid use, and risk \\ perception among young body-builders \\ from a low-income neighborhood in the city \\ of Salvador, Bahia State, Brazil
}

Jorge Alberto Bernstein Iriart 1

Tarcísio Matos de Andrade 2

\footnotetext{
1 Instituto de Saúde Coletiva, Universidade Federal da Bahia. Rua Padre Feijó 29, Salvador, $B A$ 40110-170, Brasil. iriart@ufba.br 2 Pós-graduação em Medicina e Saúde, Faculdade de Medicina, Universidade Federal da Bahia. Rua Pedro Lessa 123, Salvador, $B A$ 40110-050, Brasil. tarcisio@ufba.br
}

\begin{abstract}
Recent studies in different countries have shown an increase in anabolic steroid consumption among young people and the harm caused by indiscriminate use. In Brazil, research on steroid abuse is scarce. The present study examines the risk perception of health problems associated with anabolic steroid consumption among young working-class adults engaged in body-building practices in a poor neighborhood in the city of Salvador, Bahia. The methodology involved an anthropological approach based on qualitative research techniques consisting of ethnography, in-depth interviews, and a focus group with steroid users. The data describe the most common substances consumed and highlight the lack of information among interviewees concerning potential related health hazards, showing that for many steroid consumers the quest for muscle-mass development to achieve an idealized body supersedes the risk of harmful side effects. The results indicate the need for culturally sensitive measures to prevent steroid abuse among youth.
\end{abstract}

Key words Substance Abuse; Anabolic Steroids; Exercise; Risk Factors; Anthropology

Resumo Estudos recentes em diferentes países têm apontado o aumento do consumo de esteróides anabolizantes entre jovens fisiculturistas e atletas, e os danos à saúde causados pelo seu uso indiscriminado. No Brasil, estudos sobre o uso de anabolizantes são escassos. No presente trabalho, examina-se a percepção de risco à saúde, associada ao consumo de anabolizantes, entre jovens fisiculturistas de um bairro pobre da cidade de Salvador. A metodologia privilegiou métodos de coleta de dados qualitativos tais como etnografia, entrevistas semi-estruturadas e grupo focal com usuários de anabolizantes. Os dados produzidos descrevem as principais substâncias utilizadas e os padrões de uso, e apontam a falta de informação dos jovens entrevistados sobre a extensão dos danos à saúde decorrentes do consumo de anabolizantes, mostrando que para muitos, o desejo de desenvolver massa muscular e alcançar o corpo ideal se sobrepõe ao risco de efeitos colaterais. Os resultados indicam a necessidade de se desenvolver ações culturalmente apropriadas, voltadas para a prevenção do abuso de anabolizantes junto à essa população.

Palavras-chave Abuso de Substância; Esteróides Anabólicos; Exercício; Fatores de Risco; Antropologia 


\section{Introdução}

A crescente valorização do corpo nas sociedades de consumo pós-industriais - refletida nos meios de comunicação de massa, que expõem como modelo de corpo ideal e de masculinidade um corpo inflado de músculos - pode estar contribuindo para que um número crescente de jovens envolva-se com o uso de esteróides anabolizantes, na intenção de rapidamente desenvolver massa muscular (Courtine, 1995). O consumo dessas substâncias, especialmente entre jovens fisiculturistas e atletas, tem sido registrado com freqüência ascendente em vários países (Lise et al., 1999; Nilson, 1995; Perry et al., 1992; Scott et al., 1996) e diversos estudos têm documentado os danos à saúde causados pelo seu uso (Evans, 1997; Korkia \& Stimson, 1997; Rich et al., 1999).

Nos Estados Unidos, estudo populacional realizado em 1993 estimou em mais de um milhão o número de usuários de anabolizantes (Yesalis et al., 1993). Em relatório recente, o National Institute on Drug Abuse (NIDA, 2001) informa que a porcentagem de estudantes do curso secundário (high school) que utilizou estas substâncias cresceu $50 \%$ nos últimos quatro anos, passando de $1,8 \%$ para 2,8 . O aumento do consumo de suplementos alimentares e anabolizantes nessa população (Durant et al., 1993; Yesalis, 1997) levou o governo norte-americano a lançar, no ano passado, uma campanha nacional para alertar os jovens dos perigos associados à sua utilização (NIDA, 2001).

No Brasil, estudos que abordem o uso de anabolizantes são escassos, não existindo dados epidemiológicos que indiquem a extensão do consumo dessas substâncias. Alguns indícios, no entanto, sugerem que o uso de anabolizantes pode estar crescendo entre os jovens pertencentes a diferentes classes sociais, podendo representar, em breve, um importante problema de saúde pública. Os meios de comunicação de massa têm noticiado com alguma freqüência o consumo dessas substâncias nas academias de musculação, e chamado a atenção para os casos de efeitos colaterais graves decorrentes de seu uso abusivo (Folha de São Paulo, 2000a, 2000b). Sabe-se ainda, segundo estimativa do CEBRID (Centro Brasileiro de Informações sobre Drogas Psicotrópicas), que o consumidor preferencial no Brasil está entre os 18 e 34 anos de idade e, em geral, é do sexo masculino.

Nossa atenção para o problema originou-se no trabalho de redução de danos que o CETAD (Centro de Estudos e Terapia do Abuso de Drogas da Universidade Federal da Bahia), vem realizando em bairros populares de Salvador, e que sugere um elevado consumo de diversos tipos de anabolizantes entre jovens fisiculturistas. $\mathrm{O}$ termo fisiculturista está sendo aqui utilizado para designar os praticantes de exercícios físicos com pesos, que visam a modelagem do corpo através do desenvolvimento de massa muscular (body-building). Nos bairros populares, a prática do fisiculturismo se realiza freqüentemente em academias de musculação que funcionam em espaços improvisados e equipadas de forma precária. $\mathrm{O}$ alto consumo dessas substâncias entre os fisiculturistas, é atestado pelo grande número de seringas usadas, que são trocadas por esses jovens, junto aos agentes comunitários de saúde do CETAD, assim como pelos relatos dos cadernos de campo dos agentes que documentam o padrão de uso dessas substâncias, e os efeitos colaterais que estão produzindo entre os usuários.

Este estudo, visa contribuir para a produção de conhecimento sobre o uso de anabolizantes entre os jovens fisiculturistas das classes populares de Salvador, buscando fornecer subsídios para projetos de prevenção - assim como para redução dos efeitos nocivos decorrentes do seu uso - que sejam culturalmente apropriados junto à essa população. Os objetivos específicos são: (1) analisar os significados associados à fisicultura e as razões do uso de anabolizantes entre jovens fisiculturistas; (2) descrever as principais substâncias utilizadas, o seu padrão de uso e os efeitos colaterais percebidos e (3) analisar a percepção de risco dos usuários.

\section{Metodologia}

O presente estudo aborda o problema do abuso de esteróides anabolizantes com uma perspectiva sócio-antropológica utilizando-se, consequentemente, de métodos de pesquisa qualitativos. A escolha metodológica deve-se ao caráter exploratório do estudo e à necessidade de produzir dados em profundidade sobre o uso dessas substâncias, procurando compreender os fatores sócio-culturais subjacentes à prática da musculação e ao uso de anabolizantes.

A pesquisa foi realizada em um bairro pobre de Salvador, que tem aproximadamente 60 mil habitantes, e cujo nome será omitido para preservar a privacidade dos informantes. Assim como outros bairros periféricos das grandes cidades brasileiras, esse possui uma infraestrutura urbana extremamente precária, caracterizada pela presença de esgotos a céu aberto, ausência de unidades de saúde e áreas de lazer. Somam-se à essa realidade, o alto índice 
de desemprego da população do bairro e a forte presença do comércio ilegal de drogas, intimamente associada ao aumento da violência urbana.

Os dados aqui analisados, foram produzidos empregando-se as seguintes técnicas: (1) grupo focal, realizado com dez usuários de anabolizantes de uma academia de musculação do bairro; (2) entrevistas em profundidade (semiestruturadas), realizadas com seis informantes-chave (cinco usuários de anabolizantes e um agente de saúde do CETAD), residentes no bairro; (3) relatos transcritos ao longo de dois anos nos diários de campo de dois agentes comunitários de saúde do CETAD e (4) observação sistemática realizada pelos pesquisadores em uma academia de musculação do bairro. Trata-se de uma academia popular, equipada de forma precária, mas freqüentada regularmente por cerca de 75 fisiculturistas. Os usuários da academia são jovens das classes populares, na sua grande maioria do sexo masculino, com idades que variam de 17 a 37 anos. Eles trabalham sobretudo, no mercado informal como vigilantes, seguranças, guardadores de carro, vendedores ambulantes ou biscateiros. Alguns são estudantes e ainda não estão no mercado de trabalho. Para se exercitar na academia, cada fisiculturista paga uma mensalidade de $\mathrm{R} \$ 5,00$.

\section{Significados associados à musculação entre fisiculturistas das classes populares}

A prática da musculação - "malhação” na gíria utilizada pelos fisiculturistas - assume múltiplos significados no discurso dos jovens entrevistados. Em suas narrativas sobre as razões que os levaram a começar o trabalho de fisicultura, os informantes freqüentemente fazem alusão à admiração neles suscitada pela visão de corpos fortes e musculosos, que passam a ser tomados como modelo de corpo ideal, e servem de estímulo para o início da musculação.

"Eu comecei a treinar com 14 anos. Comecei a gostar porque eu via... eu achava bonito a pessoa com o corpo bem definido..." (fisiculturista, 29 anos).

"Um camarada meu me emprestou uma revista, eu olhei, nessa revista tinha até Arnold Schwarzenegger, então daí por diante, com menos de 18 anos, eu comecei a malhar. Como eu disse a você, né, a gente vê uma pessoa forte... e aí me interessou a musculação" (fisiculturista, 33 anos).

"Uma vontade que eu tinha de querer ficar forte, criar muitos músculos, dividir o corpo" (fisiculturista, 22 anos).
Os fisiculturistas utilizam com freqüência em sua narrativa, expressões que remetem ao "desejo de crescer", "ficar grande", "ficar forte", de forma a chamar a atenção das pessoas, através de um corpo dilatado e com "músculos bem definidos". Uma análise mais atenta dos termos utilizados pelos informantes sugere, porém, que esses transcendem a idéia de corpo físico, remetendo a uma vontade de crescer e se fortalecer subjetivamente. Em um contexto de periferia urbana - marcado pela violência, pelo tráfico de drogas e pelo desemprego que não proporciona aos jovens muitas perspectivas de construir uma identidade positiva, a fisicultura surge como uma possibilidade de construção identitária. Através do trabalho sobre o corpo, esses jovens buscam uma forma de se destacar na comunidade e de compensar uma baixa auto-estima. Uma dimensão da identidade positiva construída pelos fisiculturistas é a que enfatiza sua condição de atleta. Muito referida nas entrevistas, a percepção de si mesmo, enquanto atleta, é elemento de sua identidade capaz de opor-se à condição de desempregados/desocupados em que muitos se encontram. O corpo torna-se então, um instrumento privilegiado, por meio do qual a pessoa busca reconstruir o Eu (Self), fortalecendo uma identidade fragilizada. A repercussão externa da imagem corporal projetada, passa a ser extremamente valorizada pelos fisiculturistas, que se percebem como possuidores de um corpo modelo, símbolo de masculinidade, admirado e invejado pelos homens, e desejado pelas mulheres.

“A importância (da musculação) é a gente chegar num lugar e poder botar uma camisinha decotada, tá com os músculos trabalhado, tudo em dia, chegar numa praia e poder botar uma sunga, que tá o corpo todo trabalhado, bonitinho... (...) o pessoal começa a falar com a gente assim, tipo achar um ídolo, alguma coisa assim: 'Pô, tá forte, tá bonito, tá beleza', e param mais pra prestar atenção na gente (...)" (fisiculturista, 22 anos).

O aumento dos músculos e a sua manutenção, tornam-se uma obsessão para os fisiculturistas, que competem entre si, comparando suas medidas de braços e pernas e passando a não poupar esforços para atingir um corpo ideal. O culto ao corpo se traduz em um investimento narcísico que aparece bem evidenciado no discurso dos informantes, onde se enfatiza o prazer na admiração do próprio corpo em frente ao espelho:

“Rapaz, a gente passa a amar nosso corpo, a gostar dele, se olha no espelho com... se achando.... você se gosta mais ainda. Porque você olha 
pra sua perna e vê sua perna grossa, você olha pra seu peito e vê seu peito grande, olha pra seus bíceps e vê eles aumentando, então você passa assim, não vou dizer adorar, mas a se amar mais ainda, se cuidar mais ainda" (fisiculturista, 33 anos).

É presente no discurso dos informantes, uma freqüente insatisfação com suas medidas corporais, por maiores que essas sejam, o que remete à existência de uma dicotomia entre o corpo real e o corpo ideal. Se o corpo representa o envelope do sujeito subjetivamente constituído, entre os nossos informantes, a hiância entre o somático e o psíquico parece aumentada. Esse fato está expresso no próprio ato de malhar, onde a relação não é mais com o corpo como um todo, mas com partes do mesmo. Trabalha-se individualmente os braços, as pernas, o peito e às vezes apenas determinados grupos musculares; fala-se em corpo dividido, e se estabelece parâmetros para cada parte. O corpo é investido de uma função instrumental, tornando-se um corpo para ser visto e voltado para o consumo. Para muitos desses jovens fisiculturistas, essa função instrumental do corpo toma a forma de um investimento profissional, no qual a posse de um corpo musculoso aumenta as chances de conseguir colocação no mercado de trabalho como seguranças e vigilantes. Para outros, a exibição do corpo malhado nas festas populares da cidade, torna-se uma forma de atrair clientes homossexuais, que pagam aos fisiculturistas por seus serviços, exacerbando seu papel instrumental como fonte de renda.

\section{Substâncias utilizadas, padrões de uso e razões para o consumo de anabolizantes entre os fisiculturistas}

Os esteróides anabólico-androgênicos, comumente chamados simplesmente de anabolizantes, são substâncias sintetizadas em laboratório, relacionadas aos hormônios masculinos (androgênios). Essas substâncias aumentam a síntese protéica, a oxigenação e o armazenamento de energia resultando em incremento da massa muscular e de sua capacidade de trabalho. Na gíria popular, os anabolizantes são vulgarmente conhecidos pelo nome de "bomba” (em referência ao efeito de inchaço muscular por eles produzido), e é também comum que fisiculturistas sejam chamados pejorativamente de "bombados".

Cerca de 25 substâncias, a maioria esteróides anabólico-androgênicos, foram mencionadas pelos sujeitos da pesquisa como sendo uti- lizadas nas academias freqüentadas por eles. Essa relação também inclui hormônios femininos, usados de forma isolada ou em combinação com androgênios, e também produtos veterinários, a exemplo de complexos vitamínicos e antiparasitários. Entre os esteróides androgênicos, os mais utilizados são: Durateston (Testosterona), Stradon P (Testosterona + Estradiol) e Deca-durabolim (Nandrolona). Os hormônios femininos mais mencionados pelos informantes foram os anovulatórios Uniciclo (Algestona e Estradiol) e Premarim. O baixo poder aquisitivo dos fisiculturistas dos bairros populares, leva à opção pelos produtos mais baratos, incluindo nessa categoria os de uso veterinário. Entre esses, os mais freqüentemente mencionados foram o ADE (vitaminas A, D e E), Potenai (complexo vitamínico à base de vitamina B) e o antiparasitário Ivomec (Ivermectina).

Os dados coletados revelam que o consumo de anabolizantes tem início logo após os primeiros meses de contato dos iniciantes com os colegas de musculação na academia. A constatação de que companheiros, que iniciaram as atividades físicas na academia à mesma época, conseguiram desenvolver massa muscular consideravelmente maior, no mesmo tempo de prática, leva os novatos a procurar informações sobre as razões desse fato. A escuta e participação nas conversas entre os fisiculturistas veteranos, onde o uso de anabolizantes é um tema muito freqüente, cria a curiosidade e facilita a inserção do iniciante nos meandros de seu consumo.

P: "Como uma pessoa se inicia no uso de anabolizantes?"

R: "Primeiro é... tá vendo a pessoa que tá lá, com mais tempo de academia, aí vai se chegando, procurando saber como a pessoa tá forte... Aí, procura saber como é pra ficar forte rápido, em dois, três meses ficar... aumentar o peso rapidamente, aí o colega vai e ensina. Diz a ele. Ele procura saber o nome, a gente dá o nome, ele vai lá e compra. (...) quando eles perguntam como é que toma, tudo, a gente explica tudo direitinho a eles, como é que toma, como a gente tomou né" (fisiculturista, 22 anos).

A impaciência com o tempo necessário para o desenvolvimento da massa muscular com o exercício físico isoladamente, não se restringe, no entanto, aos iniciantes. Os veteranos também referem não se contentar com a lentidão do crescimento muscular, e com os minguados resultados obtidos por meio de uma suada musculação destituída de ajuda química. O anabolizante é visto então, como uma droga poderosa que permite ao organismo trabalhar mais rapidamente, proporcionando resultados quase 
mágicos, e recompensando imediatamente o suor despendido na malhação.

"É pra ter o resultado rápido, né, chegar rápido ao nosso objetivo, que é ficar forte, criar massa muscular, ganhar peso. A gente toma pra chegar rápido lá. Uma Decadurabolim misturada com Estradon-P, ela dá um desenvolvimento corporal bastante excessivo, chega ao ponto de aumentar um quilo e meio a dois quilos por semana, certo?" (fisiculturista, 29 anos).

"O efeito positivo é que eu tava com mais ou menos 37, 38 centímetros de braço, né? Aí foi pra 40, 42 centímetros. Aí fica todo mundo surpreso, aquele negócio, você nem acredita quando você se olha no espelho e você se vê forte" (fisiculturista, 22 anos).

As substâncias são usadas em dosagem e freqüência variáveis, determinadas pelo maior ou menor imediatismo dos fisiculturistas na aquisição de forma física desejada, pelo nível de conhecimento dos mesmos sobre essas substâncias, pelas experiências pregressas em relação aos seus efeitos colaterais e pelos recursos disponíveis para a aquisição dos produtos.

Os ciclos sistemáticos do tipo pirâmide descritos na literatura, em que o usuário utiliza doses crescentes até o final da segunda ou terceira semana, seguidas por doses decrescentes, por igual período, até o final do ciclo (NIDA, 2001), não foram observados nos dados coletados neste trabalho. O uso referido acontece de forma irregular, algumas vezes contínuo, quase diário ou com intervalos maiores, com interrupções motivadas pelos efeitos colaterais, e retorno ao uso pela falta de motivação para malhar e insatisfação com as formas corpóreas na ausência do uso de anabolizantes. Coquetéis à base de dois ou três esteróides androgênicos e ADE, são freqüentemente preparados e compartilhados pelos atletas: "O ADE vem num frasco de 50ml. A gente pega o frasco de ADE, tira $25 \mathrm{ml}$ e guarda em outro frasco, e dentro daquele $25 \mathrm{ml}$ de ADE a gente coloca $5 \mathrm{ml}$ de Durateston, coloca 10ml de Androgenol e coloca 5 Primabolan, aí mistura tudo no mesmo frasco e toma" (fisiculturista, 26 anos).

Associado ao imediatismo de resultados, presente no discurso dos informantes, encontra-se a firme suposição da impossibilidade de atingir o "corpo ideal”, que se caracteriza não apenas pela massa muscular, mas também pelo delineamento dos músculos, sem o auxílio dos anabolizantes.

“Ver alguém 'empenado' naturalmente, só com produtos naturais, ficar com o corpão enorme, todo definido, todo gigante, tem condições? Não existe! Tem que ter muito produto químico dentro do corpo!" (fisiculturista, 27 anos).
Os informantes não referem limitação da oferta dos produtos utilizados, relatando ser fácil a sua aquisição, tanto nas farmácias quanto nas casas de produtos veterinários. Os produtos importados, como o Winstrol (Stanazolol), por serem mais caros, são mais cortejados pelos fisiculturistas. A via de administração mais freqüentemente utilizada é a injetável, preferida pelos informantes por ser a mais barata e produzir um efeito imediato, embora, entre os produtos mencionados na pesquisa, alguns são disponíveis no mercado apenas para uso oral.

"Praticamente, eu gosto mais de tomar é a injetável. O efeito bate logo. Aqui, em geral, ninguém tem condição de comprar o de uso oral, pois os melhores são a partir de vinte reais" (fisiculturista, 33 anos).

O culto ao corpo musculoso, que estimula a competição entre os freqüentadores da academia pela escolha do mais forte, do que tem os músculos mais bem definidos ou de quem tem o corpo que atrai mais atenção nas ruas, contribui para o aumento do consumo de anabolizantes. Esse consumo atinge seu ápice nos meses que antecedem o carnaval, mais precisamente a partir do mês de outubro, quando os fisiculturistas se preparam para o ciclo de festas populares de verão. Nesse período, os atletas intensificam o treinamento e partilham os custos dos coquetéis de anabolizantes. O objetivo é estar com o corpo bem desenvolvido para ser exibido no verão.

\section{Efeitos colaterais e percepção de risco entre os usuários de anabolizantes}

Os múltiplos e freqüentes efeitos colaterais relacionados ao uso de anabolizantes têm sido amplamente descritos na literatura. Esses vão, desde as alterações orgânicas provocadas pelas próprias características farmacológicas dos produtos utilizados - a grande maioria deles relacionados com o hormônio masculino testosterona - habitualmente em doses muito além das fisiologicamente manejáveis pelo organismo; às infecções de transmissão sangüíneas pelo uso de equipamentos não estéreis de injeção, até os traumas locais relacionados com aplicação incorreta desses produtos. Embora seja difícil comprovar a relação causal do uso de anabolizantes e infarto agudo do miocárdio, fatores de risco como dislipidemia, alteração nos fatores da coagulação e hipertrofia do miocárdio relacionados ao uso desses produtos, têm sido registrados na literatura (Kennedy \& Lawrence, 1993). Outros importantes efeitos 
colaterais, associados ao uso de anabolizantes, descritos na literatura são a atrofia testicular, a ginecomastia e a hipertensão arterial (Korkia \& Stimson, 1997). Entre as complicações decorrentes do uso de equipamentos de injeção não esterilizados estão os abcessos cutâneos (Rich et al., 1999), a infecção pelo HIV, pelos vírus das Hepatites B e C e por outros agentes de transmissão parenteral.

De maneira geral, os fisiculturistas entrevistados não demonstram bom nível de informação sobre os danos causados à saúde pelos anabolizantes que utilizam. Os conhecimentos que possuem sobre esses produtos, muitas vezes, não guardam relação com as suas propriedades farmacológicas. As informações sobre os efeitos colaterais são sobretudo oriundas da experiência pessoal, da observação de colegas da academia e dos relatos de casos vivenciados por amigos ou conhecidos, nos quais o uso dessas substâncias acarretou sintomas graves. Os sintomas menores e temporários tais como cefaléia, náuseas, tonturas, irritabilidade, acne, febre e aumento dos pêlos corpóreos, com o tempo, passam a ser percebidos pelos usuários de anabolizantes como normais. Não transparece no discurso dos entrevistados, preocupação com os possíveis efeitos a longo prazo que o uso contínuo dessas substâncias possa produzir.

“A gente toma em uma segunda, quando é na terça a gente já sente febre, dor de cabeça, aqueles efeitos colaterais... a primeira vez que eu tomei eu fiquei com medo. Depois, todo mundo dizia que dava febre mesmo, dava dor de cabeça, eu acabei me acostumando e achando normal quando eu tomava" (fisiculturista, 29 anos).

Entre os iniciantes, que ainda não possuem bagagem empírica no uso de anabolizantes, a desinformação quanto aos seus efeitos sobre a saúde é ainda maior. No afã de rapidamente hipertrofiar seus músculos e sem consciência do risco que incorrem, eles muitas vezes exageram nas doses injetadas, na expectativa de potencializar seu efeito.

"Tem muitos caras (iniciantes) aí que a gente explicou: 'Tem que tomar tanto, tomar $1 \mathrm{ml}, 2 \mathrm{ml}$ '. Só que eles pensam que se tomar $5 \mathrm{ml}$ eles ficam mais rápido ainda. Aí acaba tomando $5 \mathrm{ml}$, como tem um caso lá recente, que um colega tomou parece que foi $10 \mathrm{ml}$ de ADE, um negócio que pra cada $50 \mathrm{~kg}$ tem que tomar $1 \mathrm{ml}$, o animal, um cavalo. Aí ele tomou $10 \mathrm{ml}$ e parou no hospital, teve convulsão" (fisiculturista, 22 anos).

Muitos informantes fizeram referência às alterações no desempenho sexual e redução do volume de esperma provocado pelo uso dos anabolizantes. Esses sintomas, porém, são tra- tados com aparente naturalidade e não levam à interrupção do uso das substâncias. Os fisiculturistas veteranos demonstram ter mais consciência dos riscos à saúde, presentes no consumo de anabolizantes. Eles referem, em seu discurso, vários efeitos colaterais como complicações locais associados à aplicação dos produtos, problemas renais, atrofia muscular atribuída ao uso de Ivermectina (Ivomec), tonturas e desmaios secundários ao uso de ADE e até mesmo infarto agudo do miocárdio.

O conhecimento do risco potencial e dos danos sofridos por outrem, não se transforma necessariamente, porém, em ação preventiva, por diversas razões. Primeiro, o desejo de fazer crescer a massa muscular e alcançar o corpo ideal, se sobrepõe ao risco potencial. Em segundo lugar, o fisiculturista percebe o risco como uma "aventura", assegurando-se, na ilusão do pensamento mágico, de que o problema nunca irá acontecer com ele.

"Todo mundo que começa a tomar esses negócios sabe que corre o risco de não dar certo né, de parar em um hospital, alguma coisa assim. Mas a gente acaba arriscando e tomando" (fisiculturista, 22 anos).

P: "Qual o risco que você acha que corre?"

$\mathrm{R}$ : "O risco que corre é da gente ter um abcesso. Tem um colega que teve um abcesso, teve que abrir o braço pra tirar, teve um colega que perdeu a perna tomando injeção localizada na perna. Esses riscos todo a gente sabe que pode acontecer com um da gente. P: E como é que vocês lidam com esse risco? R: É aquele tipo, aventura. Você pensa: 'Ah, vou aventurar. Comigo não acontece'. Aí você vê que todo mundo pensa assim" (fisiculturista, 22 anos).

A consciência do risco, presente no discurso de nossos entrevistados mostra-se frágil e fugaz. A ocorrência de algum caso de efeito colateral grave, decorrente do uso de anabolizantes na rede de relações dos usuários ou mesmo noticiado na mídia, causa um impacto apenas temporário na percepção do risco dos fisiculturistas: "Logo quando acontece assim (algum caso grave de efeito colateral) a gente fica com medo: 'Não, eu vou parar, não vou tomar mais', aquele negócio todo, pensa que se conscientizou, mas passa dois, três meses, a poeira baixa, aí todo mundo começa de novo" (fisiculturista, 22 anos).

$\mathrm{P}$ : "Sempre correndo esse risco por causa do corpo, pra manter o corpo?"

R: "Com certeza. Corre esse risco pra manter o corpo forte, manter a massa muscular" (fisiculturista, 22 anos).

A certeza de que problemas de saúde mais graves, subseqüentes ao uso de anabolizantes, 
nunca acontecerá com o usuário se reafirma a partir de sua experiência pessoal. O fato dele nunca ter percebido sintomas mais graves e conhecer pessoas, que apesar do alto consumo, nunca manifestaram maiores problemas associados ao uso dos esteróides anabolizantes, faz com que o usuário confie em que é possível utilizar essas substâncias sem comprometer a saúde.

"Eu penso assim, eu sei o que eu tô fazendo, né, eu sei que aquilo ali prejudica minha saúde. Eu tô tomando, mais sei que eu posso morrer naquela hora ali" (fisiculturista, 29 anos).

P: "Mas você prefere continuar?"

R: "Mas eu prefiro continuar... Eu acho que com fé em Deus não vai acontecer nada comigo. Até agora eu tô tranqüilo. Até agora eu não senti nada. É até pra eu fazer uma lavagem no organismo porque eu tô nessas drogas e nunca aconteceu nada comigo" (fisiculturista, 29 anos).

É comum entre os fisiculturistas entrevistados, a referência a diferentes estratégias para lidar com risco associado ao uso de anabolizantes, de forma a minorá-lo. Alguns informantes afirmam que não se sentem muito em risco porque seguem um padrão de utilização de anabolizantes que eles consideram mais seguro.

Esse padrão de uso apresenta algumas variações segundo cada usuário, e incorpora diferentes estratégias percebidas como protetoras. Entre essas, encontra-se a procura por aplicação da injeção de anabolizantes por amigos, parentes ou colegas que tenham algum curso de enfermagem ou experiência nessa prática, o que diminuiria os riscos de uma aplicação mal feita. Foi também citado como estratégia protetora por alguns, a precaução na ingestão de coquetéis, onde diferentes tipos de anabolizantes são misturados, assim como a diminuição das doses e aumento do intervalo entre uma aplicação e outra.

"Eu mesmo tomo, mas eu tomo controladamente, tomo duas vezes por mês, eu não sou igual aos outros colegas que tomam toda semana, duas, três por semana, não sabendo o efeito depois" (fisiculturista, 27 anos).

É importante ressaltar, no entanto, que algumas dessas estratégias protetoras não possuem embasamento científico ou são realizadas de forma incorreta ou pouco sistemática, o que reduz sua eficácia. É o caso, por exemplo, da muito citada prática de, periodicamente, realizar uma limpeza intestinal através da ingestão de chás e purgantes que purificariam o organismo e, supostamente, o prepararia para melhor receber novas doses de anabolizantes. Todavia, isto não possui respaldo nas características farmacológicas dos produtos utilizados.
“Eles tomam limonada Bezerra, Purgoleite. São medicamentos que eu acho que existem prá lavar o organismo, o intestino. Eles acham que tá tirando a sujeira" (Agente comunitário do CETAD).

P: "Que influência isso tem depois, no uso do anabolizante?"

R: "Eles acham que tão aptos a usar mais, que limpou, lavou tudo, e aí começa a fazer novamente o uso. (...) Isso quer dizer que o corpo tá preparado pra receber... vai fazer mal, mas ele vai resistir". P: "O corpo fica mais forte, então?" R: "Exatamente. Ficou com menos sujeira" (Agente comunitário do CETAD).

É importante também, para compreender a percepção de risco dos usuários de anabolizantes, levar em conta os seus possíveis efeitos psico-fármacológicos. Várias publicações científicas têm chamado a atenção para mudanças de humor, aumento da agressividade e dependência psíquica entre os usuários, durante o período de utilização dessas substâncias (Choi \& Pope Jr., 1994; Kleinman, 1990; Lise et al., 1999). No presente estudo, os informantes relataram dificuldade em deixar de usar anabolizantes, referindo sentir desânimo e falta de energia para malhar quando não estão sob o efeito dos mesmos. Em alguns usuários, a dependência parece se manifestar de forma semelhante à que ocorre com quem utiliza substâncias psico-ativas, produzindo comportamentos como a "fissura" que se caracteriza pela necessidade premente de consumo das substâncias.

P: "Se você parar de usar anabolizante, você sente falta?"

R: "No começo eu sentia. Quando eu parei assim, uma, duas semanas, é tipo um vício, tipo um cigarro. Dizem que cigarro não tem jeito de parar de fumar e era assim, a gente pensava que nunca ia deixar de tomar" (fisiculturista, 25 anos).

“Tem cerca de cinco usuários lá que todos os dias, o dinheiro que pegam é para comprar. Me lembra muito aquele cara fissurado em cocaína, que pega qualquer dinheiro e vai comprar um papel seja de que qualidade for. É quase a mesma coisa (...) usam todo dia e ficam naquela fissura, pedem logo a seringa: 'Vamos logo, vamos logo. Me dê logo aí que eu tomo essa pancada' (gíria usada pelos UDI para se referir à injeção de drogas)" (Agente comunitário do CETAD, notas de campo).

Por fim, o compartilhamento de seringas na aplicação do anabolizante, representa também um grande risco para a transmissão de doenças entre os usuários. A maioria dos informantes afirmou não compartilhar aparelhos de injeção e utilizar o serviço de troca de seringas, 
implantado no bairro pelo programa de redução de danos do CETAD. Entretanto, o risco do compartilhamento existe e pode encontrar terreno fértil na crença, manifesta no discurso de um informante, de que todos os fisiculturistas, pelo simples fato de investirem muito em seus corpos, são necessariamente saudáveis. Subjacente a este discurso está o imaginário, muito disseminado, de que a doença é sempre trazida pelo outro, no presente caso, aquele que não faz parte do grupo de amigos fisiculturistas.

"Esse lance de dividir seringas, tens uns que divide" (fisiculturista, 26 anos).

P: "Uma seringa para todo mundo?".

R: "Prá todo mundo não, mas um, dois, eles dividem. Mas essa galera que malha é muito difícil de ver esse negócio de doença, de AIDS, isso é muito difícil. O cara que malha ele gosta muito dele, ele não divide seringa. Mas quando ele divide, ele sabe que não vai pegar nada. Quando ele divide é porque ele tá com o camarada, aparece assim: 'Pô, vamos tomar', e bota. É muito difícil, o cara que malha assim de ter doença. Porque todo mundo que malha usa camisinha, em qualquer relação. Aí não é muito fácil ele pegar essas doenças não" (fisiculturista, 26 anos).

\section{Conclusão}

Os dados produzidos neste estudo, documentam o uso indevido de anabolizantes e os danos à saúde causados por essas substâncias, entre jovens fisiculturistas das classes populares de Salvador. O estudo analisa o consumo dessas drogas à luz do contexto sócio-cultural local e das condições psicossociais dos fisiculturistas, onde a construção do corpo musculoso e a sua exposição pública, constituem-se em importante instrumento de construção identitária, assumindo também uma função utilitária relacionada à sexualidade e à inserção no mercado de trabalho. Os dados apontam a falta de informação dos jovens entrevistados sobre a extensão dos danos à saúde decorrentes do uso de anabolizantes, mostrando que para muitos, o desejo de desenvolver massa muscular e alcançar um suposto corpo ideal se sobrepõe ao risco de efeitos colaterais.

Informações que começam a ser coletadas pelo Programa de Redução de Danos do CETAD, em bairros da periferia de Salvador, permitem supor que a realidade encontrada no bairro do estudo, provavelmente se repete em outros locais populares da cidade. O culto ao corpo, extremamente disseminado na sociedade brasileira e refletido na mídia, associado à desinformação, pode criar condições favoráveis ao abuso de anabolizantes tornando-o um significativo problema de saúde pública, como vem ocorrendo nos Estados Unidos. Há necessidade de estudos de prevalência que apontem a magnitude do consumo dessas substâncias, sobretudo entre os jovens de cidades brasileiras de médio e grande porte. Existem indícios de que o uso de anabolizantes possa estar ocorrendo significativamente também, em academias de musculação dos bairros de classe média, mas estudos qualitativos e quantitativos são necessários para verificar este fato.

Os resultados indicam a necessidade de se desenvolver ações culturalmente apropriadas, voltadas para a prevenção do abuso de anabolizantes pelos jovens fisiculturistas, ou seja, ações que levem em conta o contexto sóciocultural em que ocorre o consumo de anabolizantes e os significados que lhe são associados pelos usuários.

No que tange à prevenção junto à população de usuários no presente estudo, considerando-se o perfil dos fisiculturistas e os comportamentos de risco relacionados ao consumo de anabolizantes descritos, sugere-se a adoção dos mesmos princípios e práticas que norteiam as políticas de redução de danos entre os usuários de substâncias psico-ativas.

Essas incluem, além da orientação e informação preventiva, a provisão de preservativos, equipamentos estéreis de injeção e a criação de serviços de assistência à saúde para essa população. O aumento de consumo de anabolizantes nos meses que precedem as festas populares de verão, aponta para a necessidade de intensificação das ações preventivas nesse período do ano. 


\section{Agradecimentos}

A pesquisa foi parcialmente financiada pelo Ministério da Saúde (Coordenação Nacional de DST-AIDS) / Organização Mundial da Saúde, e o primeiro autor contou com bolsa do Conselho Nacional de Desenvolvimento Científico e Tecnológico (DCR/CNPq) durante a realização do estudo. Agradecemos também à colaboração de Jane Montes, Edward MacRae e Benimário Silva.

\section{Referências}

CHOI, P. Y. \& POPE Jr., H. G., 1994. Violence toward women and illicit androgenic-anabolic steroid use. Annals of Clinical Psychiatry, 6:21-25.

COURTINE, J. J., 1995. Os Stakhanovistas do narcisismo: Body-building e puritanismo ostentatório na cultura americana. In: Políticas do Corpo (D. B. Sant'Anna, org.), pp. 39-48, São Paulo: Estação Liberdade.

DURANT, R. H.; RICKERT, V. I.; ASHWORTH, C. S.; NEWMAN, C. \& SLAVENS, G., 1993. Use of multiples drugs among adolescents who use anabolic steroids. New England Journal of Medicine, 328: 922-926.

EVANS, N., 1997. Gym and tonic: Profile of 100 male steroid users. British Journal of Sports Medicine, 31:54-58.

FOLHA DE SÃO PAULO, 2000a. Anabolizante leva à internação psiquiátrica. Folha de São Paulo, São Paulo, 29 out., Caderno Cotidiano, p. C4.

FOLHA DE SÃO PAULO, 2000b. Pesquisa mostra números do doping em academias paulistas. Folha de São Paulo, São Paulo, 11 nov., Caderno Esportes, p. D10.

KENNEDY, M. C. \& LAWRENCE, C., 1993. Anabolic steroid abuse and cardiac death. Medical Journal of Australia, 15:346-348.

KLEINMAN, C. C., 1990. Forensic issues arising from the use of anabolic steroids. Psychiatric Annals, 20:219-221.

KORKIA, P. \& STIMSON, G. V., 1997. Indication of prevalence, practice and effects of anabolic steroid use in Great Britain. International Journal of Sports Medicine, 18:557-562.
LISE, M. L. Z.; GAMA-E-SILVA, T. S.; FERIGOLO, M. \& BARROS, H. M. T., 1999. O abuso de esteróides anabólico-androgênicos em atletismo. Revista da Associação Médica Brasileira, 45:1-11.

NILSON, S., 1995. Androgenic anabolic steroid use among male adolescents in Falkenberg. European Journal of Clinical Pharmacology, 48:9-11.

PERRY, H. M.; WRIGHT, D. \& LITTLEPAGE, B. N., 1992. Dying to the big: A review of anabolic steroid use. British Journal of Sports Medicine, 26:259261.

RICH, J. D.; DICKINSON, B. P.; FELLER, A.; PUGATCH, D. \& MYLONAKIS, E., 1999. The infectious complications of anabolic-androgenic steroids injection. International Journal of Sports Medicine, 20:563-566.

SCOTT, D. M.; WAGNER, C. J. \& BARLOW, T. W., 1996. Anabolic steroid use among adolescents in Nebraska schools. American Journal of Health-System Pharmacy, 53:2068-2072.

NIDA (The National Institute on Drug Abuse), 2001. Research Report Series. Anabolic Steroids Abuse. Washington, DC: NIDA.

YESALIS, C. E., 1997. Trends in anabolic-androgenic steroid use among adolescents. Archives of Pediatrics and Adolescent Medicine, 151:1197-1206.

YESALIS, C. E.; KENNEDY, J. C.; KOPSTEIN, N. A. \& BAHRKE, M. S., 1993. Anabolic-androgenic steroid use in the United States. JAMA, 270:1217-1221.

Recebido em 13 de junho de 2001

Versão final reapresentada em 20 de fevereiro de 2002 Aprovado em 1 de abril de 2002 